\title{
Probability Modeling of Monthly Maximum Sustained Wind Speed in Bangladesh
}

\author{
Md. Moyazzem Hossain * \\ Department of Statistics, Jahangirnagar University, Savar, Dhaka, Bangladesh
}

\begin{abstract}
Wind speed is one the most important parameter of wind energy. However, the probability density functions (pdfs) are usually used to describe the characteristics of wind speed. In literature, several pdfs have been investigated to justify the suitability of modeling the wind speed in different regions all over the world. Therefore, the choice of the pdf is very crucial. This paper, firstly find the estimates of the parameters of all probability distribution considered in this study to describe wind speed characteristics by using the maximum likelihood method and iterations were carried out with NewtonRaphson technique. Finally, the appropriate pdf for monthly maximum sustained wind speed at Coxs Bazar in Bangladesh is selected with the help of the KolmogorovCSmirnov statistic, the coefficient of determination $\left(R^{2}\right)$, the Chi-square $\left(\chi^{2}\right)$ statistic, Root mean square error (RMSE), AIC and BIC. Here, results depict that, among the distributions considered in this study, the Skewed $t$ (ST) distribution provides the best fit to the wind speed data.
\end{abstract}

Keywords Wind speed, Probability density function, maximum likelihood method, Newton-Raphson technique, Bangladesh.

AMS 2010 subject classifications 62G30, 97K80, 62H12, 80M50

DOI: $10.19139 /$ soic.v7i1.567

\section{Introduction}

Wind is now the growing technology around the world. The developments in the area of wind power generation are very inspiring, mostly in the tropical regions of Asia and Australia [1]. In the remote farms in Australia, wind power generation can play an important role ([2]; [3]). Wind is acting as fuel which is free as well as clean and it drives the turbine or used to opearte pumps for irrigation. So, wind is the renewable and substitute source of green energy [4]. The maximum sustained wind normally occurs at a distance from the center which is known as the radius of maximum wind before winds decrease at farther distances away from a tropical cyclone's center [5]. Most weather agencies use the definition for sustained winds recommended by the World Meteorological Organization (WMO), which postulates calculating wind speed at a height of 10 metres or 33 feets for 10 minutes, and then taking the average. Nevertheless, the United States National Weather Service describes the sustained winds inside tropical cyclones by taking the average of winds over a period of one minute at the same height i.e., 10 metres or 33 feets (Tropical Cyclone Weather Services Program, 2006). This is an important distinction, as the value of the highest one-minute sustained wind is about 14 percent greater than a ten-minute sustained wind over the same period [6]. The probability density function (PDF) of wind speed is used in many meteorological, oceanographical, and climatological investigations. Wanninkhof [7] studied the exchange of gas at the ocean surface as a function of wind speed PDF. Justus et al. [8] use the wind speed distribution to study the intra-annual variation in wind speed across the United States.

*Correspondence to: Md. Moyazzem Hossain (Email: mmhrs.iustat@gmail.com). Department of Statistics, Jahangirnagar University, Savar, Dhaka, Bangladesh

ISSN 2310-5070 (online) ISSN 2311-004X (print)

Copyright (C) 2019 International Academic Press 
Holland [9] make a study of turbulent atmospheric eddies at the ocean surface by using the PDFs of wind and temperature data. The use of wind speed PDF is increasing gradually in the wind power industry and here it is required to assess the power potential of different sites ([10]; [11]; [12]; [13]). In literature, it is found that different probability density functions (PDFs) have been used to describe the characteristics of wind speed which include Weibull, Rayleigh, bimodal Weibull, lognormal, gamma, etc. [14]. Celik [15] made statistical analysis of wind power density at the southern region of Turkey and summarized that Weibull model was better than Rayleigh model. Akdag et al. [16] discussed about the two component Weibull distribution and stated that WeibullWeibull gave a goodfit to the wind speed in the Eastern Mediterranean. Chang [17] used Rayleigh, Weibull and gamma distribution and its generalized form to estimate the wind energy potential. Yilmaz and Celik [18] mention that wind speed probabilities can be estimated by using probability distributions. An accurate determination of probability distribution for wind speed values is very important in evaluating wind speed energy potential of a region. Safari [19] calculate the parameters of five probability density distribution functions such as Weibull, Rayleigh, lognormal, normal and gamma in the light of long term hourly observed data at four meteorological stations in Rwanda. Hossain et al. [20] determine the best fit wind speed distribution with statistical properties of the monthly maximum sustained wind speed $(\mathrm{km} / \mathrm{h})$ of two airports in Bangladesh and they have found that Generalized Extreme Value (GEV) distribution is more accurate for modeling wind speeds of both locations.

Pobo?łkov, et al. [21] shown that 3-parameter Weibull performs as the best for modeling the wind speed at the airport in Dolny Hri?ov. Seguro and Lambert [22] considered three methods for estimating the parameters of the Weibull wind speed distribution for wind energy analysis and they recommend the maximum likelihood method for time series wind data and the modified maximum likelihood method for wind data with frequency distribution format. Petkovi?, et al. [23] used adaptive neuro-fuzzy inference system (ANFIS) to predict the annual probability density distribution of wind speed. Carta, et al. [24] stated that the the two parameter Weibull distribution presents a series of advantages with respect to the other PDFs analysed. Ouarda, et al. [25] shown that the two-component mixture distributions give a very good fit and are generally superior to non-parametric distributions in the United Arab Emirates (UAE). Ayodele, et al. [26] analyses wind speed characteristics and wind power potential of Port Elizabeth, South Africa using statistical Weibull parameters. Kidmo, et al. [27] selects a method that gives more accurate estimation for the Weibull parameters of the wind speed data of the International Airport of Garoua, Cameroon. Parajuli [28] have been statistically analyzed the wind speed data of Jumla, Nepal and show that Weibull distribution fits better than the Rayleigh distribution. Dokur, et al. [29] considers the Inverse Weibull Distribution (IWD) to analyze the wind speed potential in Bilecik, Turkey. Abdulkarim, et at. [30]compare different probability distribution function models for fitting the wind-speed data of some selected sites in northern Nigeria.

By virtue of the location of Coxs Bazar it is deemed to have abundant wind resources for grid integration of wind power. However, to date no detailed statistical analyses of wind speed characteristics of this area have been done. Therefore, this paper attempt to determine the best fit wind speed distribution of the monthly maximum sustained wind speed $(\mathrm{km} / \mathrm{h})$ with statistical properties of Coxs Bazar in Bangladesh which will be helpful for the policymekers regarding wind power generation in this area. The parameters of the probability distribution is carried out with the help of maximum likelihood method and Newton-Raphson iterative technique where it requires. Also, to assess the goodness-of-fit of the fitted PDFs to the monthly maximum sustained wind speed data, the KS, the $R^{2}$, the $\chi^{2}$, the RMSE, AIC and BIC were used in this paper.

The rest of this paper is organized as follows. Section 2 briefly discusses the theoretical concepts of different probability distributions and goodness-of-fit tests used in this study. Results have been presented in section 3 . Finally, section 4 , is dedicated to the conclusions.

\section{Materials and Methods}

\subsection{Data Source}

This study select the Coxs Bazar station which is a coastal area of Bangladesh and here there is an unbroken 120 $\mathrm{km}$ sandy sea beach (one of the world's longest beach) with a gentle slope. The secondary data set of monthly 
maximum sustained wind speed were collected for the selected meteorological station over the period January, 1982 to October, 2016. The location map is displayed in Figure 1.

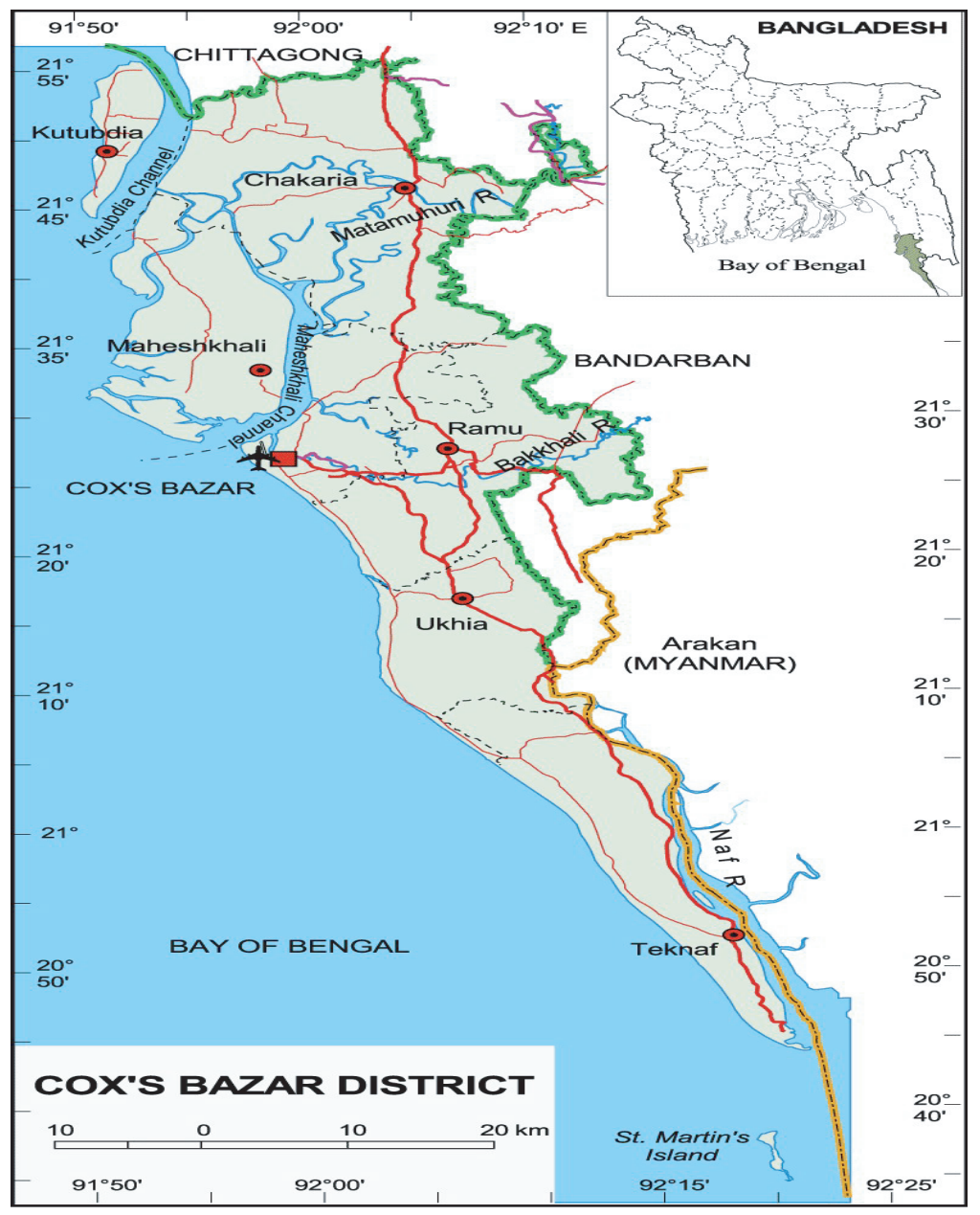

Figure 1. Location Map of the study area

\subsection{Probability Distributions}

2.2.1. Weibull (W) Distribution The probability density function (PDF) of the Weibull distribution with two parameters is given by (Weibull [31]):

$$
f(v, k, c)=\frac{k}{c}\left(\frac{v}{c}\right)^{k-1} \exp \left[-\left(\frac{v}{c}\right)^{k}\right] ; 0<v<\infty, k>0, c>0
$$

where, $k$ and $c$ are the shape and scale parameters respectively.

2.2.2. Lognormal $(L N)$ Distribution Lognormal distribution is a probability distribution of a random variable whose logarithm is normally distributed. The probability density function (PDF) of the Lognormal distribution is given by (Johnson et al. [32]):

$$
f(v, \mu, \sigma)=\frac{1}{v \sqrt{\left(2 \pi \sigma^{2}\right)}} \exp \left[\frac{-(\ln (v)-\mu)^{2}}{2 \sigma^{2}}\right] ; 0<v<\infty, 0<\mu<\infty, \sigma>0
$$


where, $\mu$ and $\sigma$ are the mean and standard deviation of the normal random variable $\ln (v)$ respectively.

2.2.3. Gamma $(G)$ Distribution Lancaster [33] quotes from Laplace [34] in which the latter obtains a Gamma distribution. The probability density function (PDF) of the gamma distribution is given by:

$$
f(v, a, b)=\frac{v^{a-1}}{b^{a} \Gamma(a)} \exp \left(\frac{-v}{a}\right) ; v>0, a>0, b>0
$$

The parameters $a$ and $b$ are the shape and scale parameters respectively.

2.2.4. Generalized Gamma (3-P G) Distribution The generalized gamma also known as three parameters gamma distribution is a continuous probability distribution with three parameters. For non-negative $v$, the probability density function of the generalized gamma is (Stacy [35]):

$$
f(v, a, d, p)=\frac{\frac{p}{a^{d}} v^{d-1} \exp -\left(\frac{v}{a}\right)^{p}}{\Gamma\left(\frac{d}{p}\right)} ; v>0, a>0, d>0, p>0
$$

where, $a$ and $d$ are the scale and shape parameters respectively, $p$ is the threshold and $\Gamma($.$) denotes the gamma$ function.

2.2.5. Generalized Extreme Value (GEV) Distribution GEV distribution is a flexible model that combines the Gumbel, Frechet and Weibull maximum extreme value distributions (Ying and Pandey [36]). For, GEV the probability density function is given by:

$$
f(v, \mu, \sigma, \xi)=\frac{1}{\sigma}\left[1+\xi\left(\frac{v-\mu}{\sigma}\right)\right]^{\left(\frac{-1}{\xi}\right)-1} \exp \left[-\left[1+\xi\left(\frac{v-\mu}{\sigma}\right)\right]^{-\frac{1}{\xi}}\right] ; \xi \neq 0
$$

where, $\mu \in \mathbf{R}$ is the location parameter, $\sigma>0$ the scale parameter and $\xi \in \mathbf{R}$ is the shape parameter.

2.2.6. Three Parameters Lognormal (3-P LN) Distribution The lognormal distribution derives its name from the relationship that exists between random variables $V$ and $Y=\ln (V-a)$. If $Y$ is distributed normally $(b, c)$, then $V$ is lognormal $(a, b, c)$. Accordingly, the probability density function of $V$ may be written as (Cohen and Whitten [37]):

$$
f(v, a, b, c)=\frac{1}{(v-a) c \sqrt{(2 \pi)}} \exp \left[\frac{-[\ln (v-a)-b]^{2}}{2 c^{2}}\right] ; a<v<\infty, 0<a<\infty, \dot{6} 0
$$

where, $b$ and $c$ are the location and shape parameters respectively and $a$ is the threshold.

2.2.7. Skewed $t$ (ST) Distribution The Skewed $t$ Distribution (STD) was suggested by Arellano-Valle and Azzalini [38] and the probability density function (pdf) is given as follows:

$$
f(v)=\frac{2}{2 \theta_{1} \theta_{2}^{\frac{1}{2}} \beta\left(\frac{1}{2}, \theta_{2}\right)\left[1+\frac{\left|v-\theta_{0}\right|^{2}}{\theta_{2} \theta_{1}^{2}\left[1+\operatorname{sgn}\left(v-\theta_{0}\right) \theta_{3}\right]^{2}}\right]^{\frac{1}{2}+\theta_{2}}} ;-\infty<v<\infty, \theta_{1}>0, \theta_{2}>0,-\infty<\left(\theta_{0}, \theta_{3}\right)<\infty
$$

where, $\theta_{0}$ and $\theta_{1}$ are the location and scale parameters respectively, $\theta_{2}$ and $\theta_{3}$ are the degrees of freedom and shape parameters respectively and $\beta$ is the beta function.

2.2.8. Generalized Skewed Logistic (GSL) Distribution Perks [39] first introduced the generalized logistic distribution. Zeileis and Windberger [40] wrote a R Package 'glogis' for Fitting and Testing Generalized Logistic Distributions and they used the following probability density function (pdf) of the generalized skew logistic distribution:

$$
f(v, a, b, c)=\frac{\gamma}{\sigma} \frac{\exp \left(-\frac{v-\mu}{\sigma}\right)}{\left[1+\exp \left(-\frac{v-\mu}{\sigma}\right)\right]^{\gamma+1}} ; 0<v<\infty
$$

where, $\mu, \sigma$ and $\gamma$ are the location, scale and shape parameters respectively. 


\subsection{Goodness-of-fit Tests}

2.3.1. Kolmogorov-Smirnov (KS) Error Test The KS test computes the largest difference between the cumulative distribution function of the model and the empirical distribution function and several studies this test (Justus, et al. [41]; Justus, et al. [42]; Tuller and Brett [43]; Poje and Cividini [44]; Chang [17]; Qin, et al. [45]; Usta and Kantar [46]). The KS test statistic is defined as $D=\max _{1<i<n}\left|F_{i}-\hat{F}_{i}\right|$ where, $\hat{F}_{i}$ is the predicted cumulative probability of the $i^{\text {th }}$ observation obtained with the theoretical cdf and $F_{i}$ is the empirical probability of the $i^{t h}$ observation are obtained with the Cunnane [47] formula: $F_{i}=\frac{i-0.4}{n+0.2}$ where, $i=1, \ldots, n$ is the rank for ascending ordered observations.

2.3.2. $R^{2}$ Test The $R^{2}$ is the coefficient of determination associated with the PCP probability plot which plots the theoretical cdf versus the empirical cumulative probabilities and is used widely for goodness-of-fit comparisons (Garcia, et al. [48]; Celik [15]; Akpinar and Akpinar [49]; Li and Li [12]; Ramirez and Carta [50]; Carta, et al. [24]; Morgan [51]; Soukissian [52]; Zhang, et al., [53]) and hypothesis testing because it quantifies the correlation between the observed cumulative probabilities and the predicted cumulative probabilities of a distribution. A larger value of $R^{2}$ indicates a better fit of the model cumulative probabilities $\hat{F}$ to the observed cumulative probabilities $F$. The $R^{2}$ is defined as $R^{2}=\frac{\sum_{i=1}^{n}\left(\hat{F}_{i}-\bar{F}\right)^{2}}{\sum_{i=1}^{n}\left(\hat{F}_{i}-\bar{F}\right)^{2}+\sum_{i=1}^{n}\left(F_{i}-\hat{F}_{i}\right)^{2}} ; \bar{F}=\frac{\sum_{i=1}^{n} \hat{F}_{i}}{n}$.

2.3.3. Chi-Square Error Test Chi-Square test is used to assess whether the observed probability differs from the predicted probability (Auwera, et al., [54]; Conradsen, et al., [55]; Dorvlo [56]; Akpinar and Akpinar [49]; Chang [17]). The Chi-Square test statistic is defined as $\chi^{2}=\sum_{i=1}^{n} \frac{\left(F_{i}-\hat{F}_{i}\right)^{2}}{\hat{F}_{i}}$, where, $\hat{F}_{i}$ is the predicted cumulative probability of the $i^{t h}$ observation obtained with the theoretical cdf.

2.3.4. Root Mean Squared Error (RMSE) Test Root mean square error (RMSE) provides a term-by-term comparison of the actual deviation between observed probabilities and predicted probabilities. A lower value of RMSE indicates a better distribution function model. Root mean square error (RMSE) is defined as (Hossain, et al., [20]) $R M S E=\left[\frac{\sum_{i=1}^{n}\left(F_{i}-\hat{F}_{i}\right)^{2}}{n}\right]^{\frac{1}{2}}$, where, $\hat{F}_{i}$ is the predicted cumulative probability of the $i^{t h}$ observation obtained with the theoretical cdf.

\subsubsection{Akaike Information Criterion (AIC) and Bayesian Information Criterion (BIC) Test The Akaike} Information Criterion (AIC) and Bayesian Information Criterion (BIC) are defined as $A I C=e^{\frac{2 k}{n}} \frac{\sum_{i=1}^{n} \hat{u}^{2}{ }^{2}}{n}$, $B I C=e^{\frac{\sum_{n}^{n}}{n} \frac{\hat{u}_{i}{ }^{2}}{n}}$, where, $\sum_{i=1}^{n} \hat{u}_{i}{ }^{2}=\sum_{i=1}^{n}\left(F_{i}-\hat{F}_{i}\right)^{2}$,

here, $\hat{F}_{i}$ is the predicted cumulative probability of the $i^{t h}$ observation obtained with the theoretical cdf, $k$ is the number of estimated parameters and $n$ is the number of observations. 


\section{Results}

The descriptive statistics of monthly maximum sustained wind speed for the selected station in this paper are presented in Table 1. From the given table, it is observed that the minimum value of the monthly maximum sustained wind speed is $5.4 \mathrm{~km} / \mathrm{h}$ which is observed in November however, the maximum value is $110.7 \mathrm{~km} / \mathrm{h}$ and observed in August. Whereas the highest average of maximum sustained wind speed is $35.01 \mathrm{~km} / \mathrm{h}$ with standard deviation $18.32 \mathrm{~km} / \mathrm{h}$ and the lowest average of maximum sustained wind speed is $24.23 \mathrm{~km} / \mathrm{h}$ having standard deviation $20.08 \mathrm{~km} / \mathrm{h}$.

Table 1. Descriptive statistics of monthly maximum wind speed $(\mathrm{km} / \mathrm{h})$ for Coxs Bazar station.

\begin{tabular}{|l|l|l|l|l|l|l|l|l|l|l|l|l|}
\hline Statistic & Jan & Feb & Mar & Apr & May & Jun & Jul & Aug & Sep & Oct & Nov & Dec \\
\hline Mean & 26.66 & 26.04 & 31.08 & 31.18 & 35.01 & 29.21 & 33.99 & 31.24 & 31.26 & 28.51 & 24.23 & 25.85 \\
\hline $\begin{array}{l}\text { Standard } \\
\text { Deviation }\end{array}$ & 18.87 & 14.11 & 21.69 & 15.06 & 18.32 & 12.37 & 19.06 & 22.23 & 22.83 & 22.47 & 20.08 & 20.96 \\
\hline Kurtosis & 1.84 & 14.38 & 2.70 & 7.16 & 1.10 & 0.12 & 2.45 & 4.49 & 1.58 & 2.70 & 4.29 & 4.08 \\
\hline Skewness & 1.70 & 3.20 & 1.80 & 2.19 & 1.26 & 0.92 & 1.74 & 2.16 & 1.60 & 1.88 & 2.14 & 2.15 \\
\hline Minimum & 9.40 & 7.60 & 9.40 & 13.00 & 13.00 & 14.80 & 13.00 & 13.00 & 9.40 & 7.60 & 5.40 & 7.60 \\
\hline Maximum & 75.90 & 92.40 & 92.40 & 92.40 & 83.20 & 55.40 & 92.40 & 110.7 & 92.40 & 92.40 & 92.40 & 92.40 \\
\hline
\end{tabular}

The parameters of all the PDFs considered in this study are estimated by using maximum likelihood method and estimated parameters of different PDFs considered in this paper for identifying the most suitable probability distribution are presented in Table 2.

The statistical parameters for fitness evaluation of PDFs currently analyzed are presented in Table 3. Considering K-S error, $\chi^{2}$ error, RMSE, AIC and BIC we may conclude that the Weibull, lognormal, Gamma, three parameters Gamma, GSL, three parameters lognormal and GEV has large errors indicating their inadequacy in modeling monthly maximum wind speed for Coxs Bazar station whereas the higher value of $R^{2}$ and the lower values of K-S error, RMSE, chi square error, AIC and BIC indicate that Skewed $t$ (ST) distribution is more accurate than other PDFs in modeling monthly maximum wind speed for Coxs Bazar station.

Several studies also performed a visual assessment of fitted pdfs. They have superimposed on the histograms of wind speed data (Nfaoui, et al., [57]; Archer and Jacobson [58]; Ulgen, K. and Hepbasli [59]; Kose, et al., [60]; Jaramillo, et al., [61]; Chang [17]; Chellali, et al., [62]; Qin, et al., [45]). The graphical comparison of different probability distribution considered in this study and the histogram of the observed monthly maximum wind speed of Coxs Bazar is presented in Figure 2.

Figure 2 depicts the frequency histograms and normal probability plot of wind speed and all the probability distribution have been employed in this study are superimposed in this plot. As seen from Figure 2, Skewed $t$ (ST) provided the best fit for the observed monthly maximum wind speed for Coxs Bazar station.

\section{Conclusion}

Actually, wind is a form of solar energy and is generated due to the rough heating of the atmosphere by the sun, the anomalies of the earths surface, and revolution of the earth. The earths terrains, bodies of water, vegetative cover are the factors used to modify the wind flow patterns. Wind energy is a very clean and environmentally renewable energy. Considering the wind speed characteristic it is believed that wind energy has a bright prospect and significantly towards the solution of energy crisis in Bangladesh. This paper suggest that the monthly maximum wind speed was fluctuated over the study period in every month. Considering K-S error, $\chi^{2}$ error, $R^{2}$, RMSE, AIC and BIC we may conclude that the Skewed $t$ (ST) provided the best fit for the observed monthly maximum wind speed for Coxs Bazar station which will be helpful to characterize the main features of the maximum sustained wind speed at Coxs Bazar in Bangladesh. Also, the graphical comparison of different distributions shows the same result. This paper suggest to use the Skewed distribution to describe the characteristics of wind speed at Coxs 
Table 2. Estimated parameters of different PDFs considered in this study.

\begin{tabular}{|c|c|c|c|c|}
\hline PDF & Parameters & Estimated value & $t$ value & $p$ value \\
\hline W & Shape $(k)$ & 1.69471 & 28.98 & $<0.001$ \\
& Scale $(c)$ & 33.42521 & 33.65 & $<0.001$ \\
\hline LN & Mean $(\mu)$ & 3.22099 & 118.93 & $<0.001$ \\
& Standard Deviation $(\sigma)$ & 0.55369 & 28.91 & $<0.001$ \\
\hline G & Shape $(a)$ & 3.1897 & 15.72 & $<0.001$ \\
& Scale $(b)$ & 9.262 & 14.59 & $<0.001$ \\
\hline GEV & Shape $(\xi)$ & 0.28271 & 7.21 & $<0.001$ \\
& Scale $(\sigma)$ & 20.2213 & 37.48 & $<0.001$ \\
& Location $(\mu)$ & 9.843561 & 21.91 & $<0.001$ \\
\hline 3-P G & Shape $(d)$ & 2.0578 & 13.81 & $<0.001$ \\
& Scale $(a)$ & 11.9117 & 13.31 & $<0.001$ \\
& Threshold $(p)$ & 5.0306 & 18.85 & $<0.001$ \\
\hline 3-P LN & Shape $(b)$ & 0.63558 & 16.57 & $<0.001$ \\
& Scale $(c)$ & 3.07432 & 52.92 & $<0.001$ \\
& Threshold $(a)$ & 2.89046 & 3.13 & $<0.001$ \\
\hline ST & Location $\left(\theta_{0}\right)$ & 12.3180 & 9.45 & $<0.001$ \\
& Scale $\left(\theta_{1}\right)$ & 14.5307 & 3.57 & $<0.001$ \\
& Degrees of Freedom $\left(\theta_{2}\right)$ & 3 & 2.94 & 0.003 \\
& Shape $\left(\theta_{3}\right)$ & 4.4969 & 2.38 & 0.02 \\
\hline GSL & Location $(\mu)$ & 32.33 & 42.82 & $<0.001$ \\
& Scale $(\sigma)$ & 11.54 & 34.76 & $<0.001$ \\
& Shape $(\gamma)$ & 109.72 & 143.94 & $<0.001$ \\
\hline
\end{tabular}

Table 3. Values of Statistical tests for different distributions of Coxs Bazar stations.

\begin{tabular}{|c|c|c|c|c|c|c|}
\hline PDF & $K-S$ Error & $R^{2}$ Error & $\chi^{2}$ Error & $R M S E$ Error & AIC & BIC \\
\hline W & 0.12811 & 0.91779 & 6.74737 & 0.07561 & 0.00577 & 0.00589 \\
LN & 0.06924 & 098455 & 1.21550 & 0.03518 & 0.00125 & 0.00127 \\
G & 0.11179 & 0.95314 & 3.79731 & 0.06063 & 0.00371 & 0.00378 \\
GEV & 0.05192 & 0.99629 & 0.34382 & 0.01739 & 0.00031 & 0.00032 \\
3-P G & 0.09275 & 0.96897 & 2.41587 & 0.04884 & 0.00242 & 0.00249 \\
3-P LN & 0.06207 & 0.99003 & 0.85064 & 0.02806 & 0.00080 & 0.00082 \\
ST & 0.05008 & 0.99800 & 0.15282 & 0.01294 & 0.00017 & 0.00018 \\
GSL & 0.09101 & 0.96828 & 2.86293 & 0.05226 & 0.00277 & 0.00285 \\
\hline
\end{tabular}

Bazar which is also used to make decision in order to utilize the wind energy as an alternative energy source since it may offer many environmental as well as economical advantages compared to fossil fuels based energy sources polluting the lower layer atmosphere. Therefore, it is right time to explore and implement the wind energy technology without any further delay.

\section{Acknowledgement:}

The author is grateful to the University Grants Commission of Bangladesh for providing the financial support in the year 2015-2016 through the faculty of physical and mathematical science, Jahangirnagar University, Bangladesh. The author also thankful to the Jahangirnagar University, Bangladesh for providing the opportunity to conduct this research and permission to publish this paper on the journal. Again, the author would like to give thanks to the 


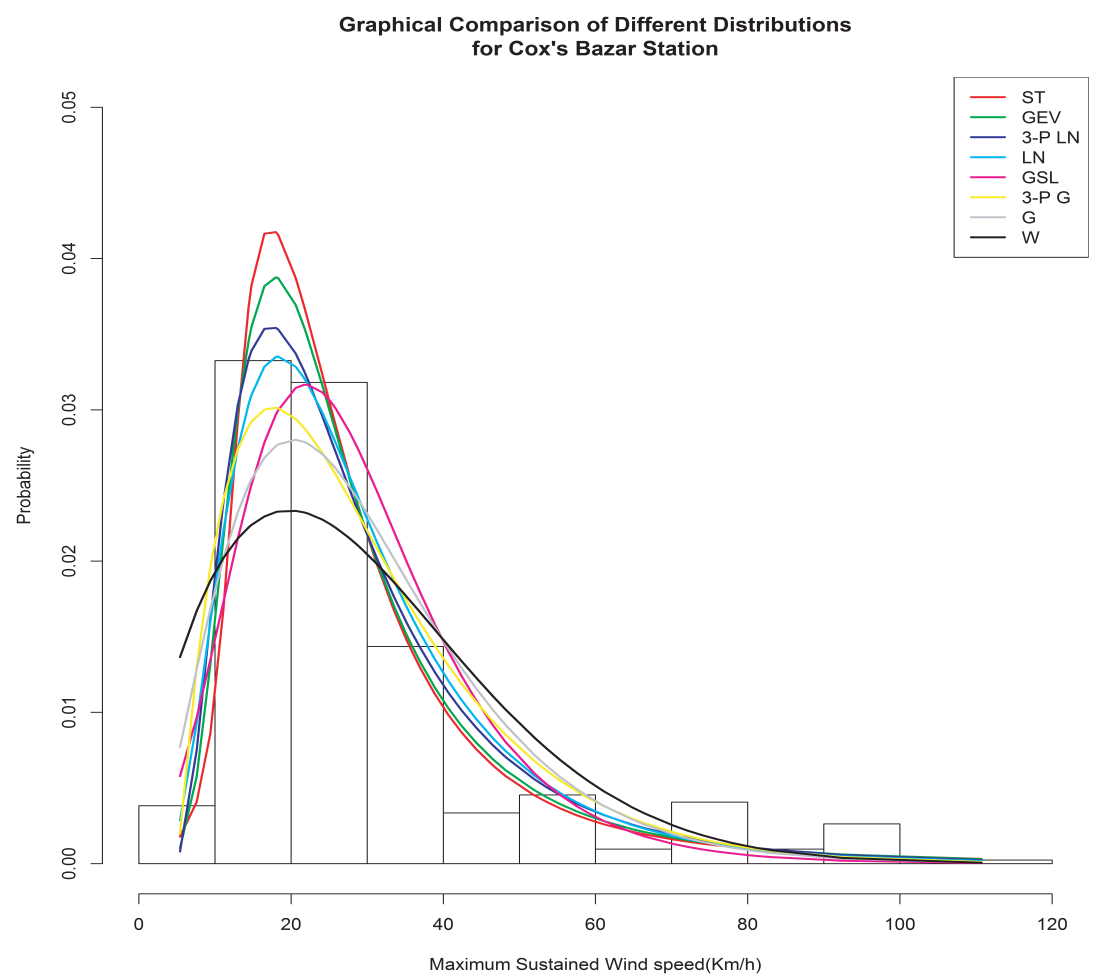

Figure 2. Graphical Comparison for different distributions of maximum wind speed of Coxs Bazar station

editor and anonymous referees for careful checking the manuscript and provide the comments and suggessions which helps to improve the quality of the paper.

\section{REFERENCES}

1. Mandal, A. C. and Islam, M. Q., Aerodynamics and Design of Wind Turbines, Bangladesh University of Engineering and Technology, Dhaka, Bangladesh, 2001.

2. Hossain, M. A. and Islam, M. Q., Sailwing Rotor for Pumping Water in Bangladesh, Renewable Energy Review Journal, 4(1), 29-35, 1982.

3. Azad, A. K., Alam, M. M. and Islam, M. R., Statistical Analysis of Wind Gust at Coastal Sites of Bangladesh, International Journal of Energy Machinery, 3(1), 9-17, 2010.

4. Suresh, R. and Block, D. S., Field Testing of Geared Type Deep Well Wind Pumps in India, Journal of Wind Engineering, 22(2), $117-129,1998$.

5. Blanchard, B. W. and Hsu, S. A., On the Radial Variation of the Tangential Wind Speed outside the Radius of Maximum Wind during Hurricane Wilma, Louisiana: Coastal Studies Institue, Louisiana State University, 2005.

6. Jan-Hwa Chu, Section 2. Intensity observation and forecast errors, United States Navy, 1999.

7. Wanninkhof, R., Relationship between wind speed and gas exchange over the ocean, J. Geophys. Res., 97, 7373-7382, 1992.

8. Justus, C. G., Mani, K. and Mikhail, A. S., Inter-annual and month-to-month variations of wind speed, J. Appl. Meteor., 18, 913-920, 1979.

9. Holland, J. Z., A statistical method for analyzing wave shapes and phase relationships of fluctuating geophysical variables, J. Phys. Oceanogr., 3, 139-155, 1973.

10. Hennessey, J. O., Some aspects of wind power statistics, J. Appl. Meteor., 16, 119-128, 1977.

11. Garcia-Bustamante, E., Gonzalex-Rouco, J. F., Jimenez, P. A., Navarro, J. and Montavez, J. P., The influence of the Weibull assumption on monthly wind energy estimation, Wind Energy, 11, 483-502, 2008.

12. Li, M., and Li, X., MEP-type distribution function: A better alternative to Weibull function for wind speed distributions, Renew. Energy, 30, 1221-1240, 2005.

13. Lackner, M. A., Rogers, A. L. and Manwell, J. F., Uncertainty analysis in MCP-based wind resource assessment and energy production estimation, J. Sol. Energy Eng., 130, 031006, 2008. doi:10.1115/1.2931499. 
14. Kollu, R., Rayapudi, S. R., Narasimham, S. V. L. and Pakkurthi, K. M., Mixture probability distribution functions to model wind speed distributions, International Journal of Energy and Environmental Engineering, 3, 27, 2012. doi:10.1186/2251-6832-3-27.

15. Celik, A. N., A statistical analysis of wind power density based on the Weibull and Rayleigh models at the southern region of Turkey, Renew. Energy, 29, 593-604, 2003.

16. Akdag, S. A, Bagiorgas, H. S. and Mihalakakou, G., Use of two component Weibull mixtures in the analysis of wind speed in the Eastern Mediterranean, Applied Energy, 87(8), 2566-2573, 2010.

17. Chang, T. P., Estimation of wind energy potential using different probability density functions, Applied Energy, 88(5), 1848-1856, 2011.

18. Yilmaz, V. and Celik, H. E., A statistical approach to estimate the wind speed distribution: the case of Gelibolu region, Do?u? niversitesi Dergisi, 9(1), 122-132, 2008.

19. Safari, B., Modeling wind speed and wind power distributions in Rwanda, Renewable and Sustainable Energy Reviews, 15(2), 925-935, 2011.

20. Hossain, M. M., Abdulla, F. and Majumder, A. K., A Study on Monthly Maximum Wind Speed Probability Distributions at Hazrat Shahajalal and MAG Osmani International Airport of Bangladesh, Jahangirnagar University Journal of Science, 39(2), 11-22, 2016.

21. Pobo?łkov, I., Sedlia?kov, Z, and Michalkov, M., Application of four probability distributions for wind speed Modeling, Procedia Engineering, 192, 713-718, 2017.

22. Seguro, J. V. and Lambert, T. W., Modern estimation of the parameters of the Weibull wind speed distribution for wind energy analysis, Journal of Wind Engineering and Industrial Aerodynamics, 85(1), 75-84, 2000. Doi: 10.1016/S0167-6105(99)00122-1.

23. Petkovi?, D., Shamshirband, S., Tong, C.W., Al-Shammari, E.T., Generalized adaptive neuro-fuzzy based method for wind speed distribution prediction, Flow Measurement and Instrumentation, 43(1), 47-52, 2015. Doi: 10.1016/j.flowmeasinst.2015.03.003.

24. Carta, J. A., Ramłrez, P. and Velzquez, S., A review of wind speed probability distributions used in wind energy analysis: Case studies in the Canary Islands, Renewable and Sustainable Energy Reviews, 13(5), 933-955, 2009. Doi: 10.1016/j.rser.2008.05.005.

25. Ouarda, T. B. M. J., Charron, C., Shin, J. Y., Marpu, P. R., Al-Mandoos, A. H., Al-Tamimi, M. H., Ghedira, H., and Al Hosary, T. N., Probability distributions of wind speed in the UAE, Energy Conversion and Management, 93, 414-434, 2015. Doi: 10.1016/j.enconman.2015.01.036.

26. Ayodele, T. R., Jimoh, A. A., Munda, J. L., and Agee, J. T., Statistical analysis of wind speed and wind power potential of Port Elizabeth using Weibull parameters, Journal of Energy in Southern Africa, 23(2), 30-38, 2012.

27. Kidmo, D. K., Danwe, R., Doka, S.Y., and Djongyang, N., Statistical analysis of wind speed distribution based on six Weibull Methods for wind power evaluation in Garoua, Cameroon, Revue des Energies Renouvelables, 18(1), 105-125, 2015.

28. Parajuli, A., A Statistical Analysis of Wind Speed and Power Density Based on Weibull and Rayleigh Models of Jumla, Nepal, Energy and Power Engineering, 8, 271-282, 2016. Doi: 10.4236/epe.2016.87026.

29. Dokur, E., Kurban, M., Ceyhan, S., Wind speed modelling using inverse weibull distrubition: a case study for Bilecik, Turkey, International Journal of Energy Applications and Technologies, 3(2), 55-59, 2016.

30. Abdulkarim, A., Abdelkader, S. M., Morrow, D. J., Falade, A. J. and Adediran, Y. A., Statistical analysis of wind speed for electrical power generation in some selected sites in northern Nigeria, Nigerian Journal of Technology, 36(4), 1249-1257, 2017. Doi: $10.4314 /$ njt.v36i4.35.

31. Weibull, W., A statistical distribution function of wide applicability, J. Appl. Mech. Trans., 18(3), 293-297, 1951.

32. Johnson, N. L., Kotz, S., Balakrishnan, N., 14: Lognormal Distributions, Continuous Univariate Distributions. Vol. 1., Wiley Series in Probability and Mathematical Statistics: Applied Probability and Statistics (2nd ed.), New York: John Wiley and Sons, 1994.

33. Lancaster, H. O., Forerunners of the Pearson Chi-square, Australian Journal of Statistics, 8, 117-126, 1966.

34. Laplace, P. S., Theorie Analytique des Probabilities, 1836.

35. Stacy, E. W., A Generalization of the Gamma Distribution, Annals of Mathematical Statistics, 33(3), 1187-1192, 1962.

36. Ying, A., and Pandey, M. D., The $r$ largest order statistics model for extreme wind speed estimation, J. Wind Eng. and Aerodyn., 95(3), 165-182, 2007.

37. Cohen, A. C. and Whitten, B. J., Estimation in the Three-Parameter Lognormal Distribution, Journal of the American Statistical Association, 75, 399-404, 1980.

38. Arellano-Valle, R. B. and Azzalini, A., The centered parameterization and related quantities of the skew $t$ distribution, Journal of Multivariate Analysis, 113, 73-90, 2013

39. Perks, W. F., On some experiments in the graduation of mortality statistics, Journal of the Institute of Actuaries, 58, 12-57, 1932.

40. Zeileis, A. and Windberger, T., Fitting and Testing Generalized Logistic Distributions, Package glogis, CRAN, 2014.

41. Justus, C. G., Hargraves, W. R., and Yalcin, A., Nationwide assessment of potential output from wind-powered generators, J. Appl. Meteorol., 15(7), 673-678, 1976.

42. Justus, C. G., Hargraves, W. R., Mikhail, A., and Graber, D., Methods for estimating wind speed frequency distributions, J. Appl. Meteorol., 17(3), 350-353, 1978.

43. Tuller, S. E., and Brett, A. C., The goodness of fit of the Weilbull and Rayleigh distribution to the distributions of observed wind speeds in a topographically diverse area, J. Climatol., 5, 74-94, 1985.

44. Poje, D. and Cividini, B., Assessment of wind energy potential in croatia, Solar Energy, 41(6), 543-554, 1988.

45. Qin, Z. L., Li, W. Y. and Xiong, X. F., Estimating wind speed probability distribution using kernel density method, Electric Power Syst. Res., 81(12), 2139-2146, 2011.

46. Usta, I. and Kantar, Y. M., Analysis of some flexible families of distributions for estimation of wind speed distributions, Applied Energy, 89(1), 355-367, 2012.

47. Cunnane, C., Unbiased plotting positions C a review, J. Hydrol., 37(3-4), 205-222, 1978.

48. Garcia, A., Torres, J. L., Prieto, E., and De Francisco, A., Fitting wind speed distributions: a case study, Solar Energy, 62(2), 139-144, 1998.

49. Akpinar, E. K., and Akpinar, S., A statistical analysis of wind speed data used in installation of wind energy conversion systems, Energy Convers. Manage., 46(4), 515-532, 2005. 
50. Ramirez, P. and Carta, J. A., The use of wind probability distributions derived from the maximum entropy principle in the analysis of wind energy: A case study, Energy Convers. Manage., 47(15-16), 2564-2577, 2006.

51. Morgan, E. C., Lackner, M., Vogel, R. M., and Baise, L. G., Probability distributions for offshore wind speeds, Energy Convers. Manage., 52(1), 15-26, 2011.

52. Soukissian, T., Use of multi-parameter distributions for offshore wind speed modeling: the Johnson SB distribution, Applied Energy, 111, 982-1000, 2013.

53. Zhang, J., Chowdhury, S., Messac, A., and Castillo, L., A multivariate and multimodal wind distribution model, Renew Energy, 51, 436-447, 2013.

54. Auwera, L., Meyer, F. and Malet, L., The use of the Weibull three-parameter model for estimating mean power densities, J. Appl. Meteorol., 19, 819-825, 1980.

55. Conradsen, K., Nielsen, L. B., and Prahm, L. P., Review of Weibull statistics for estimation of wind speed distributions, J. Climate Appl. Meteorol., 23(8), 1173-1183, 1984.

56. Dorvlo, A. S. S., Estimating wind speed distribution, Energy Convers. Manage., 43(17), 2311-2318, 2002.

57. Nfaoui, H., Buret, J., and Sayigh, A. A. M., Wind characteristics and wind energy potential in Morocco, Solar Energy, 63(1), 51-60, 1998.

58. Archer, C. L. and Jacobson, M. Z., Spatial and temporal distributions of U.S. winds and wind power at $80 \mathrm{~m}$ derived from measurements, J. Geophys Res: Atmosph., 108(D9), 4289, 2003.

59. Ulgen, K., and Hepbasli, A., Determination of Weibull parameters for wind energy analysis of Izmir, Turkey, Int. J. Energy Res., 26(6), 495-506, 2002.

60. Kose, R., Ozgur, M. A., Erbas, O. and Tugcu, A., The analysis of wind data and wind energy potential in Kutahya, Turkey, Renew. Sustain. Energy Rev., 8(3), 277-288, 2004.

61. Jaramillo, O. A., Salda?a, R., and Miranda, U., Wind power potential of Baja California Sur, Mxico, Renew. Energy, 29(13), 2087-2100, 2004.

62. Chellali, F., Khellaf, A., Belouchrani, A., and Khanniche, R. A., comparison between wind speed distributions derived from the maximum entropy principle and Weibull distribution, Case of study; six regions of Algeria, Renew. Sustain. Energy Rev., 16(1),379$385,2012$. 